\title{
Field Data Collection for Land Information Systems - A Case Study on Quantification of Resource Requirement for a GIS
}

\author{
E.A.G. Chandramali and N.T.S. Wijesekera
}

\begin{abstract}
Field data collection is the most important component for application development. Field data significantly affect the results of a research or a project. Therefore it would consume a substantial period of time unless field data collection is suitably designed, properly planned and executed with minimum gap fill data collection efforts. It is important for field data collection programs to carefully ascertain the required data, accuracy requirements and incorporate suitable verification tools. In order to achieve success of this process it is necessary to have a well organised methodology to evaluate available methods and tools for data collection, gap filling, verification and evaluation. This must be achieved through a good literature review, and then selecting and creating suitable methods, requirements and resources for data collection. The study area is around university of Moratuwa in Moratuwa DSD of Sri Lanka. It is a semi urban area of approximately $2.5 \mathrm{~km}^{2}$ with nearly 6000 buildings and 300 roads. The area was divided into ten zones for data collection purpose. Georeferenced Google images, a pre tested data collection sheet, printed maps, Magellan Triton Handheld GPS and 38 data collectors were the resources used for the data collection process to capture spatial data. Total number of buildings collected from the survey is 5175 which covered the $17.97 \%$ of the extent. 469 Roads with a total length of $52,920 \mathrm{~m}$ and classified into six road types covered $5.99 \%$ of the total area. The data capturing rate was approximately 5.5 ha of land area and $3.8 \%$ of building units per averaged person per day. To capture these data, collectors travelled $162.5 \mathrm{~km}$ within the data collection area consuming 102 person days. This research provides a systematic approach and guideline quantifications supporting GIS planners to prepare project estimations.
\end{abstract}

Keywords: $\quad$ Land Data Management, GIS, Field Data, Guideline, Resource Planning, Moratuwa, Sri Lanka

\section{Introduction}

Almost all forms of human activities and interests are based on the Land and hence land is considered as a very valuable resource which if not properly managed would lead to conflicts that are not only local but also international. Land Management is the process whereby resources of the land are optimally utilized for human activities seeking technological advancement, economic opportunities, environmental sustenance, etc., with pressures of population growth [2][3][4]. Though land information contains all information whether on surface, underground or above, most land information systems are dealing with those on the surface of earth and they are associated with land use. Once the data that are to be incorporated to an information system are determined, it is then necessary to ensure that an appropriate land information database, a suitable user interface and reliable data collection programs etc., are embedded with standardisation and quality control.

While emphasising the need for the preparation of field maps depicting boundaries, and measurements and compilation of village maps in a land information system [18], indicates the importance of standardisation of land database preparation. Yeboah and Johansson [10] carrying out the preparation of an Urban Management Land Information System has identified quality control as a very important part of the database preparation. In this work while a questionnaire had been used to collect

Ms. E.A.G.Chandramali, B.Sc. (Hons )in IT . (SLIIT), M.Sc in Civil Engineering. (University of Moratuwa), Graduate Student, Department of Civil Engineering, University of Moratuwa, Sri Lanka

Eng. (Prof.) N.T.S.Wijesekera, B.Sc. Eng. (Sri Lanka), PG Dip.(Moratuwa), M. Eng. (Tokyo), D.Eng. (Tokyo), C. Eng., MICE (UK), FIE (Sri Lanka), Senior Professor of Civil Engineering, Department of Civil Engineering, University of Moratuwa, Sri Lanka. 
property information, aerial photographs and othophotos had been used for mapping buildings. It had also been reported that work that had to be carried out to link building data to the digital map had been extensive. Many field data collection programs for GIS databases focus on the GPS data collection methods and accuracies [12][14].

In literature there are many documents describing Land Information Systems, data needs, development methods and templates [11] which discuss about parameters, accuracies and monitoring required [1]. Though there are guidelines on the selection of equipment for GIS data collection, it can be noted that literature on the details of data collection, design of field forms, handling of data types, data checks, data adequacy, data coding etc., are limited [6]. Studies indicating quantified assessments of labour, time and accuracy requirements are very important for engineering applications and also for research. In literature there are no such quantifications through systematic Scientific assessments.

Unless field data collection is carried out in a systematic well planned manner, a significant time loss in the base data preparation would cause many difficulties in achieving user requirements together with resource wastage. Present work describes the field data collection experiences for preparation of a GIS for land data. This work uses a combination of the literature reported methods, experiences, lessons learnt, recommendations etc... This also combines a planning process which included a rational approach for implementation.

Overall objective of the case study included the (i) Identification of the needs of Land Information Management using a GIS and associated data requirements, (ii) Identification of key factors for design of the database, planning of the field data collection needs and to carryout field data collection, (iii) Identification of the field data distribution of the study area and to capture the issues and considerations with respect to field data collection for Land GIS. The specific objective was to carryout the collection of building unit and road data of a study area in the Moratuwa Divisional Secretariat Division (DSD) of the Western Province, in order to prepare a GIS for land data management.

\section{Study Area}

The study location having an extent of approximately $2.46 \mathrm{~km}^{2}$ is a semi urban area around the University of Moratuwa in Moratuwa DSD of Sri Lanka. The boundary coordinates are $101769.48 \mathrm{~m} \mathrm{E}, 176467.398 \mathrm{~m} \mathrm{~N}$ and $178124.358 \mathrm{~m} \mathrm{E}, 104010.22 \mathrm{~m} \mathrm{~N}$. These coordinates are based on the GCS_Kandawala geographical coordinate system (D_Kandawala datum). Figure 1 shows the location of the study area with Google satellite image [15] observed at an altitude of 300 meters used as the background. Study area has a mixed representation of residential and commercial building units together with a distribution of low, middle and high income groups. This area was opted for the study due to its close proximity to the university since it would enable data collection and verification with minimum cost.

\section{Methodology}

\subsection{Planning of data collection}

The proposed database for land information is to provide spatially distributed land information. Since buildings and roads are two major types of land uses [4], and also because both belong to different data types, these two would be representative for a typical case study. There are two methods to identify a particular building or a spatial entity. One is to identify a building by its own attributes and the other method is to identify a building relative to an external feature. In the present study roads were taken as the external referencing feature. Therefore the database contained three main components as (i) The background image, (ii) Building data, and (iii) Road data.

The GIS was planned to display land features (e.g. buildings and roads) according to its geographic location while providing the attribute data such as details of location, nature, purpose and unique value. A mosaic of the project area map was prepared with the JPEG imagery downloaded from the Google site. This mosaic was georeferenced using 1: 10,000 topographic sheets and the GPS coordinates of known points captured using a Magellan Triton 2000 handheld GPS Unit.

In the present study, each buildings and roads were to possess the attributes shown in Figure 2. Each building was treated as main units and sub units when assigning Reference Number. A building unit or a sub unit with a postal address reference was considered as a spatial entity. Number of floors in the main unit, purpose of the unit; whether a temporary or a permanent structure, roof cover type and wall colour of the sub unit were the main attribute data that were targeted. In case of road 


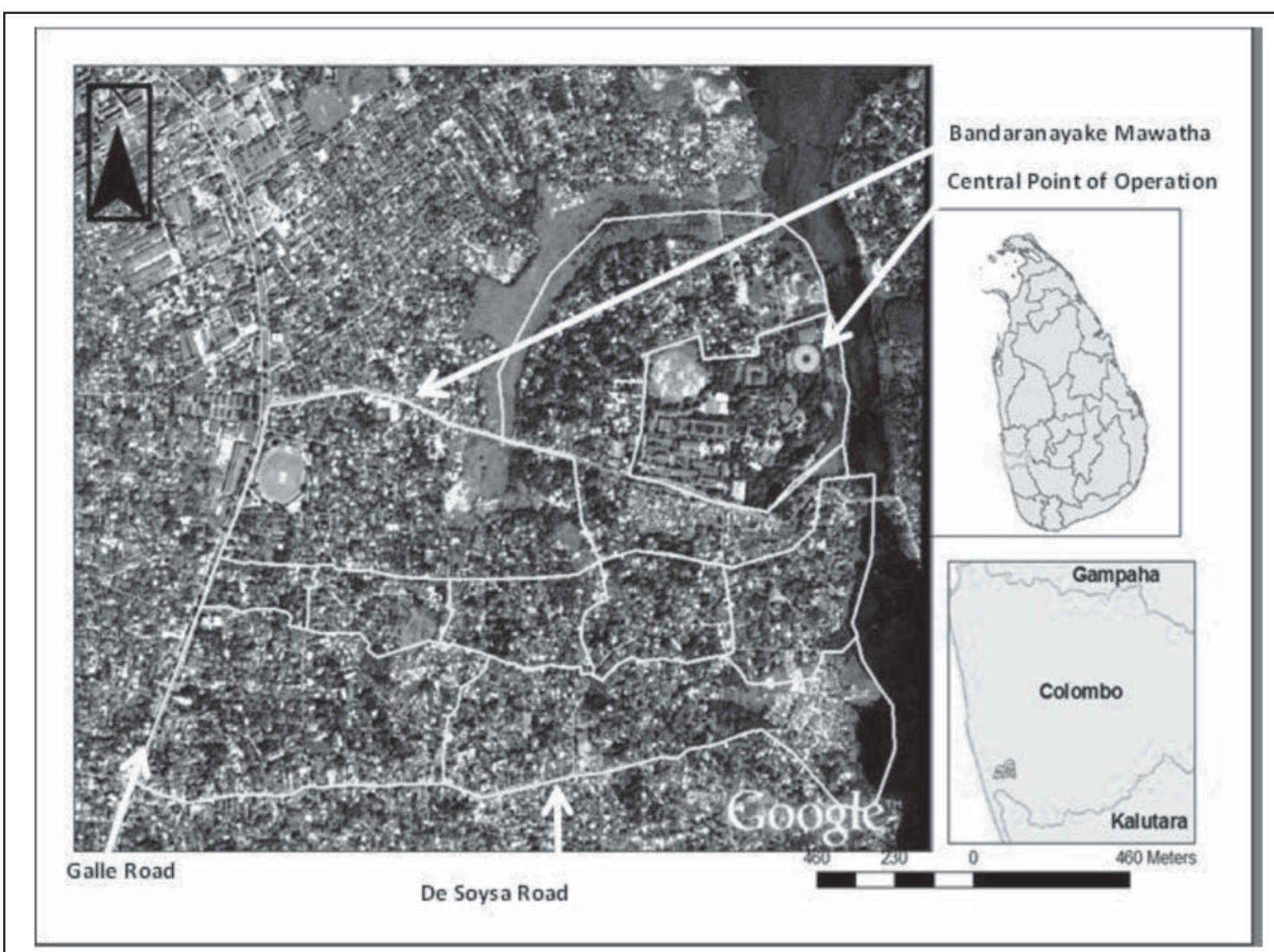

Figure 1 - Study Area and Data Collection Zones for Data Collection

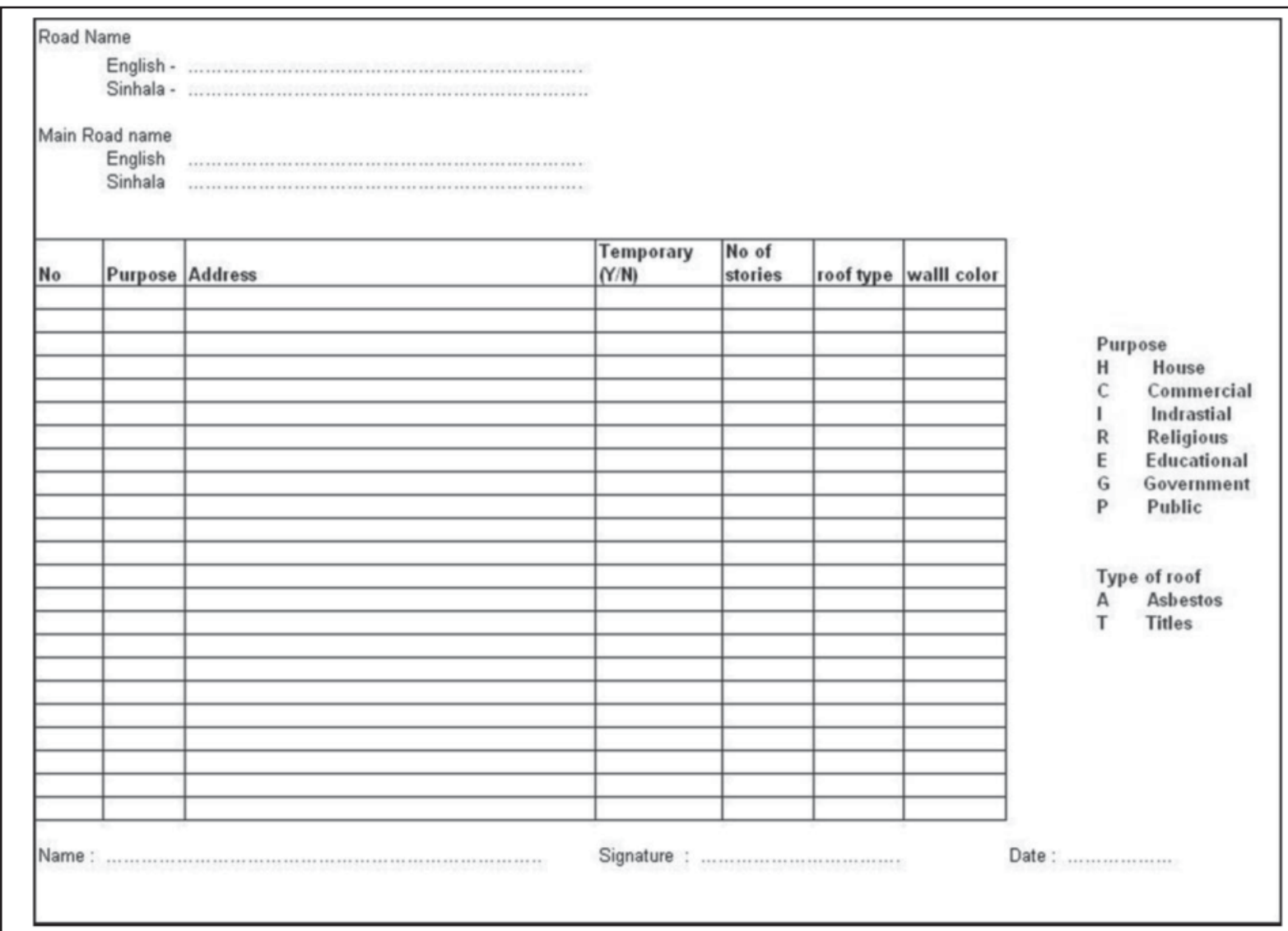

Figure 2 - Initial Data Collection Sheet 
features a serial number, notations, aaa features, a serial number, name of road, type, road name in English and Sinhala, and road reference with respect to a destination or an origin were taken as attribute data.

Literature cited formats and factors were studied [10][8] to design a simple data collection form for easy capturing and verification of data. A tabular format which could be easily taken to the field as an individual A4 sheet was first designed for field data capture (Figure 2). Data form was designed to capture buildings considering the main access to the unit and by separating units to each road. In the data sheet, top left hand corner was assigned for road information recording because they are common for a set of buildings. Data collection with the sheet was to be carried out with simultaneous GPS measurements. Data collectors were given the Google image of the area for use as a guide map and also to mark the location of a road or dwelling unit of which data were captured using the form (Figure 3). Road and building detail capture was with the intention of picking the purpose of each dwelling/building, nature of structure, and number of floors. The roof type and the colour of front wall were also included to enable data verifications using a combination of Google image and field visits. Initial field data collection sheet which also was with a guide for purpose and roof type codes is shown in Figure 2.

\subsection{Data Form Testing}

Forms were handed to experienced data collectors who had a training on the use of handheld GPS. Group of data collectors were given an explanation on data capturing and its objectives, a print out of the map to a scale of 1:1500 for marking concerned roads and buildings, data collection forms and a handheld GPS unit to capture location of houses and track the travel paths.

Initial testing of the questionnaire was done within the university compound about $0.2 \mathrm{~km}^{2}$ in area. Six data collectors in two groups were deployed along the same path to independently duplicate data collection. Data collection was done at non overlapping times to enable a thorough testing of the questionnaire for user clarity. Initial testing revealed the need of entering data according to floor number, need of a sub unit concept due to multiple uses, need of a clear unambiguous coding to save time, along with improvements to the data classifications. Road information recording improvements such as inclusion of both Sinhala and English names was identified during trial testing. Top right band of the form was assigned to print the attribute classification. These attributes to be captured in the field were classified and pre coded for easy data entry and these codes were printed on every data form for easy reference. Remaining band at the bottom of the paper was in a tabular form at where each row was designed to capture details of a building unit. During this trial testing, data collectors did not have to cover a large distance. Data capturing coverage was closely monitored. GPS tracks were taken and waypoints were established at locations where feature information could not be captured by interacting with stakeholders.

After improvements to the data collection forms and after the initial testing, field data collection outside the university premises was carried out with 14 data collectors. In this data collection five groups were used. Four groups with three members and one with two members enabled further improvements to the data collection form for its clarity and completeness. A major issue identified at this testing was the need to capture and insert building units which were either constructed subsequent to the base map preparation or were hidden from Google image due to land cover. GPS coordinates of these units were taken and incorporated to the main geodatabase after verification with adjacent field data. Mobile phones were used for clarifications among groups and from the supervisors. Final set of attributes incorporated to the form are given in the Table 1 . Classifications, notations and format used for data collection are shown in Figure 4.

Table 1 - List of Feature Attributes

\begin{tabular}{|r|l|l|}
\hline $\begin{array}{l}\text { N } \\
\text { o }\end{array}$ & $\begin{array}{l}\text { Attributes of } \\
\text { Buildings }\end{array}$ & Attributes of Roads \\
\hline 1 & Main Unit & Road Number \\
\hline 2 & Floor Number & $\begin{array}{l}\text { Type: Main Road/By } \\
\text { Road }\end{array}$ \\
\hline 3 & Sub Unit & Road Name English \\
\hline 4 & Purpose & Road Name Sinhala \\
\hline 5 & Postal Address & $\begin{array}{l}\text { Road From (Link } \\
\text { Reference) }\end{array}$ \\
\hline & $\begin{array}{l}\text { Sub Unit Status: } \\
6\end{array}$ & \begin{tabular}{l} 
Pemporary/ \\
\hline 7
\end{tabular} \\
\hline 8 & Rermanent & \\
\hline 9 & Rall Colour & \\
\hline
\end{tabular}




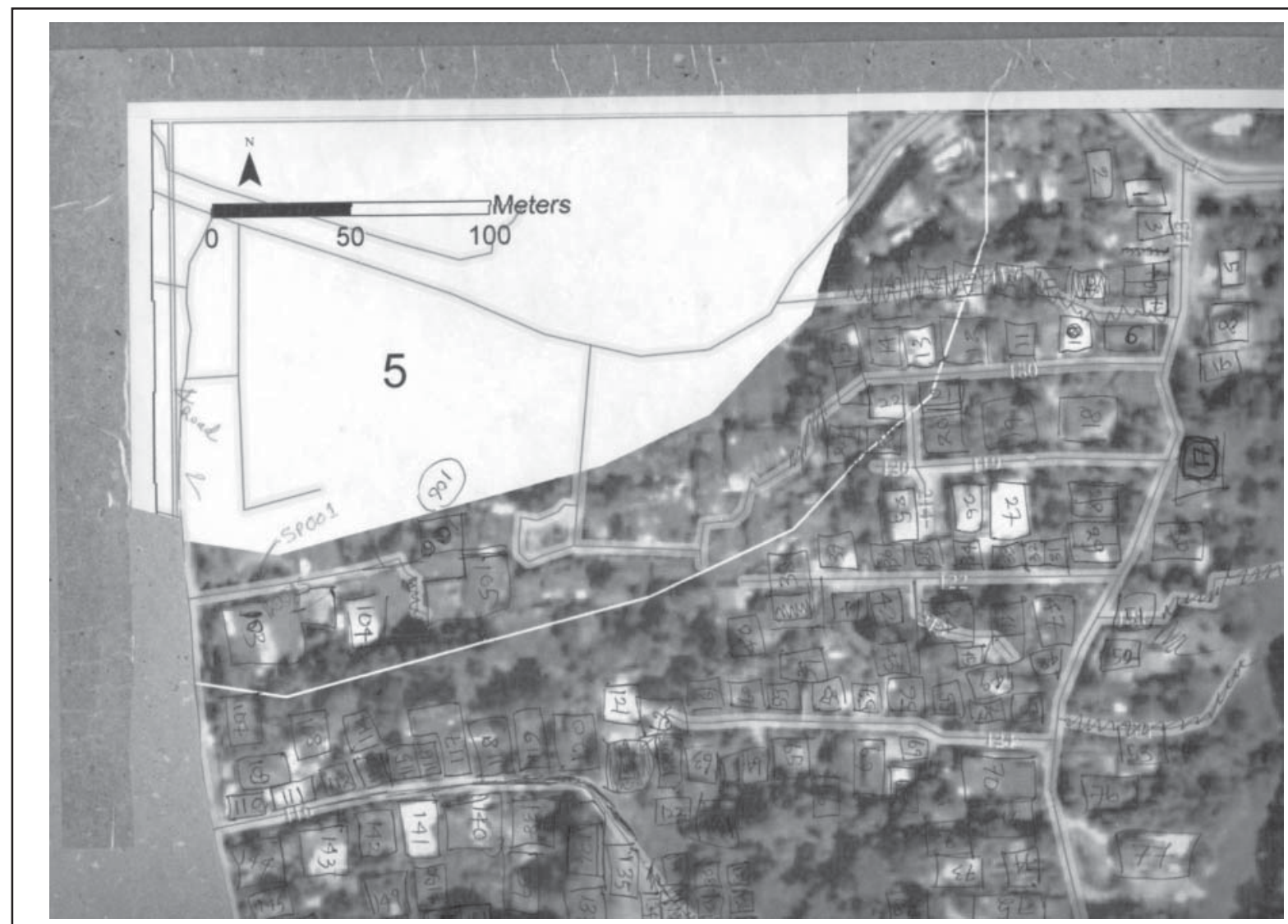

Figure 3 - Buildings Identified in the Field were Marked on the Printed Map

Study area was divided as zones for easy data

\begin{tabular}{|c|c|c|c|c|c|c|c|c|}
\hline \multicolumn{9}{|c|}{ MORATUWA MAP UPDATING PROJECT - UNIVERSITY OF MORATUWA } \\
\hline \multirow{2}{*}{\multicolumn{5}{|c|}{$\begin{array}{l}\text { Road No.......... } \\
\text { This road is a Main Road / By Road (Delete as Applicable) }\end{array}$}} & \multirow{2}{*}{\multicolumn{2}{|c|}{\begin{tabular}{|l|l|} 
Roof & Class \\
A Asbestos
\end{tabular}}} & Purpose of Unit & Floor Number \\
\hline & & & & & & & L $\quad$ Living & B- Basement (B1, B2 etc) \\
\hline Road Name & \multicolumn{4}{|c|}{ This road is a Main Road/By Road (Delete as Applicable) } & \multicolumn{2}{|c|}{$\begin{array}{l}\text { Asbestos } \\
\text { Tiles }\end{array}$} & Commercial & G - Ground Level \\
\hline \multicolumn{2}{|c|}{ Rd Nm English - ............................. } & \multicolumn{3}{|c|}{ Road From:....................... } & \multicolumn{2}{|c|}{ Local Tiles } & Industrial & $1-1^{\text {st }}$ Floor \\
\hline \multicolumn{5}{|c|}{ Rd Nm Sinhala -... } & \multicolumn{2}{|c|}{ Z Zinc Sheets } & Religious & $2-2^{\text {nd }}$ Floor \\
\hline \multicolumn{5}{|c|}{ Give Connected main road name } & \multirow{2}{*}{\multicolumn{2}{|c|}{\begin{tabular}{|ll} 
C & Coconut Leaves \\
0 & Oher (Specify)
\end{tabular}}} & Educational & \\
\hline \multirow{2}{*}{\multicolumn{5}{|c|}{$\begin{array}{l}\text { Main Rd Nm English - ....................... } \\
\text { Main Rd Nm Sinhala } \ldots \ldots \ldots \ldots \ldots \ldots \ldots \ldots\end{array}$}} & & & Government & \\
\hline & & & & & & \begin{tabular}{|l|l|} 
P & Public \\
\end{tabular} & \\
\hline \multicolumn{4}{|c|}{ Data Collector Name: } & \multicolumn{3}{|l|}{ Signature: } & $0 \quad$ Oher (Specify) & \\
\hline $\begin{array}{l}\text { Sat Map } \\
\text { Ref. No } \\
\text { Main } \\
\text { Unit } \\
\end{array}$ & Floor № & Sub Unit No & $\begin{array}{c}\text { Purpose of } \\
\text { Unit }\end{array}$ & \begin{tabular}{|c|} 
House \\
Number of \\
Unit \\
(Postal \\
Address) \\
\end{tabular} & \begin{tabular}{|l|} 
Temp/Perm \\
Unit (T/P) \\
\end{tabular} & $\begin{array}{l}\text { Ro of } \\
\text { Class(Type) }\end{array}$ & Walll Color & Remarks \\
\hline & & & & & & & & \\
\hline & & & & & & & & \\
\hline & & & & & & & & \\
\hline & & & & & & & & \\
\hline & & & & & & & & \\
\hline & & & & & & & & \\
\hline
\end{tabular}

Figure 4 - Format of the Final Data Collection Sheet

\subsection{Date Collection}

Study area was divided as zones for easy data collection (Figure 1). Zone demarcation was based on the satellite image of the area and the initial field visits. Land area that has to be covered, travel distance along roads, ease of sequential capturing, and approximate number of units in a specific area, the strengths of male and female data collectors in a group were the factors considered during the zoning. Since the size of the study area and the number of features that required to be captured were 
significant, data collection program had to vary the number of collectors from time to time. This required the zoning to be made dynamic. The G-Zones (Figure 1) were made smaller because they were chosen for first stage of field data capturing enabling easy verification and modifications. The other area grouped as TZones were divided considering the experience and the data collectors assigned to each group. Central point of operation for data program was the International Center for Geoinformatics Applications and Training (ICGAT) of the Moratuwa University. In order to satisfy security concerns of the country during the data collection time, collectors were provided with certified identity cards indicating the university involvement and contact phone numbers etc., for constant wear.

Initial data collection was done with four numbers of three-person groups and one twoperson group. Main activities that had to be undertaken were the interaction with stakeholders, identification of map reference and GPS position, and feature data recording. Data collection was done on two main data collection periods.

Initially, full-scale data collection in the G-Zone was done during a two day period (from $15^{\text {th }}$ to $16^{\text {th }}$ June 2009). Data collectors group sizes were small and experience of travelling in the project area was minimal. Data collection form used for this testing was fresh from initial testing. During the second data collection from the 1-4th July 2009 in the T-Zones, the group sizes were increased enabling a coordinated group activity with two members dedicated to collect data from left side and the right side of road, with one person locating and recording on the map and the other handling the GPS and filling the data forms. The group of five enabled more specific task division by dividing the GPS handling and filling of data forms. The data collection in the second period had approximately $20 \%$ data collectors common to both periods and lead and guided other collectors. Data capturing for the University premises was carried out with the data form testing exercises using a total of six data collectors in two groups.

At the time of data collection, the need for road data was recognized and a five class system as, follows was used. (I) Class 1: 4 lane roads, (II) Class 2: 2 Lane roads (III) Class 3: 1 lane roads and facilities for overtaking (IV) Class 4: 1 lane and no facilities for overtaking normal vehicles and suitable for three wheelers. (V) Class 5: motor bicycle/foot paths. Data collectors used a form for each road segment. Therefore, it was possible for each data collection team to subsequently assess the road types in the study area which were missed in early data collection. Gap fill data collections also enabled road classifications that had been left out by the data collectors during the initial runs.

\subsection{GPS measurements}

Field locations were captured using Magellan Triton handheld GPS units loaded with the satellite image as background. Data collectors were trained to (I) Operate the GPS, (II) Ensure that the settings are correct; (III) Ascertain that satellite coverage is adequate and (IV) Capable of recording and storing of way points and track data. Data collectors were also given training on map reading and comparing the map of GPS unit with the printed Guide map. Data collectors were also given instructions to observe the path of travel on map together with a comparison of features for easy positioning.

GPS coordinates at the start of a road and at the end were captured by the field staff. For some buildings, data capturing could not be completed due to the absence of house occupants. When such were experienced, a GPS waypoint was taken and a note was made in the field map carried by the data collectors for subsequent gap filling. GPS way points of buildings were taken either at the door step or in the garden of each building. Visited roads and places were tracked with the handheld GPS by using a selected tracking interval of 20 seconds enabling the capturing of road turning points with sufficient detail. Tracking was done for gapfill data capturing mainly of the roads and also for the field data verification while waypoints were used for building and other location identification.

\subsection{Verification and Gap Filling}

Field data verification was done at different stages. Two supervisory personnel who were the project leaders carried out independent checks at randomly selected locations using the hard copy map of the respective area used for marking by a particular group. The GPS was used to find the mapped places of concern. Roof type and wall colour were taken as the main attributes for verification. At a few locations detailed verification of the entire data set attributes including address, usage etc..., was carried out.

Guide map for each group was prepared with a clear demarcation of assigned boundaries but for easy referencing, feature details of a buffer 
zone was included in the map. Initial data collection reports showed a significant overlap data collection at the zone boundaries. This was because of the variation of access to a particular area that was experienced in the field when compared with that estimated with the satellite image. As the data collection program continued, it was also noted that there were regions near the boundary of the zones that had been over looked by the collectors. Once the recorded data sheets were received by the supervisory personnel, checks were made to ascertain the coverage of data. When there were overlaps, such data were used for data collection verifications. If omissions were identified then data collectors were again assigned for gap-fill data collection. The methods such as mobile phone communications, end of the day discussions and quick screening of data sheets and maps were tools used for data verification.

Filled data entry forms were taken over by the database preparers for the preparation of the GIS. The georeferenced base maps were used as the background for digital data entry in GIS software. Checks were performed to identify the accuracy of entered data.

\section{Results and Discussion}

\subsection{Data Coverage}

Buildings and Usage: Initial Google map interpretation and digitising of building polygons prior to field visits by observing the land cover enabled an estimated existence of 6226 buildings. Field data collections identified a total of 5175 main buildings units which contained 5384 sub unit identities (Table 2) which were recognised by separate postal addresses. Within this total, there were 478 buildings without complete details because they were either under construction, abandoned, demolished or did not have a person either in the house or in the neighbourhood to respond to the data collectors. A close assessment revealed that the initial Google image-based interpretations during digitizing had misinterpreted the colour of several land covers. In this there had been a mistaken identification of land cover as roofs. Therefore, the overall error in building identification in the project area using satellite views was a $20.3 \%$ over estimation. The Zonal details provided a good indication of the building density in each zone with a variation between 0.14 and 0.26 and having a mean value of 0.18 building area coverage per unit area.
Figure 5 shows photographs of data collector groups carrying out field work.

Building usage was recognised as 10 classes. In addition to 8 classes that were initially identified, the final data collection required inclusion of two more classes since there were many units having more than one purpose and some without a specific purpose. The category labelled as other contained the purposes that were other than those specifically listed in the data collection legend. Distribution of the units according to the purpose is shown in the Table2. Majority of the units were for living (81\%) and the next highest was for commercial purposes with a percentage value of $11 \%$. There were 164 units (3\%) classified as without a purpose.

Table 2 - Distribution of Building Units According to the Purpose

\begin{tabular}{|l|l|l|}
\hline \multicolumn{1}{|l|}{ Purpose } & $\begin{array}{l}\text { Number of } \\
\text { Units }\end{array}$ & $\%$ Coverage \\
\hline Living & 4348 & $80.76 \%$ \\
\hline Commercial & 591 & $10.98 \%$ \\
\hline Industry & 47 & $0.87 \%$ \\
\hline Religious & 32 & $0.59 \%$ \\
\hline Education & 92 & $1.71 \%$ \\
\hline Government & 16 & $0.30 \%$ \\
\hline Public & 34 & $0.63 \%$ \\
\hline Other & 41 & $0.76 \%$ \\
\hline Multi purpose & 19 & $0.35 \%$ \\
\hline Without purpose & 164 & $3.05 \%$ \\
\hline Total & 5384 & $100 \%$ \\
\hline
\end{tabular}

Roads: Roads classified in to five classes are shown in the Table 3. An additional class had to be identified since there were small road sections leading to a single house unit or to housing compound and was not for common use. These were named as private roads. There were 4 road segments in the study area without a specific name or an identity. Total length of public roads where at least a 3-wheeler could travel was $21 \mathrm{~km}$. 366 common foot/motor bicycle paths scattered in the study area were having a total length of $25.8 \mathrm{~km}$ and this was $49 \%$ of all roads in the study area. This narrow Type -5 roads averaging to about $1.2 \mathrm{~m}$ in width were significantly high because of very thickly populated informal settlement regions which had many small houses next to each other and separated by a foot or a cycle path.

Google image based road length estimations prior to field data collection was $43.1 \mathrm{~km}$ consisting of 296 segments but the field 


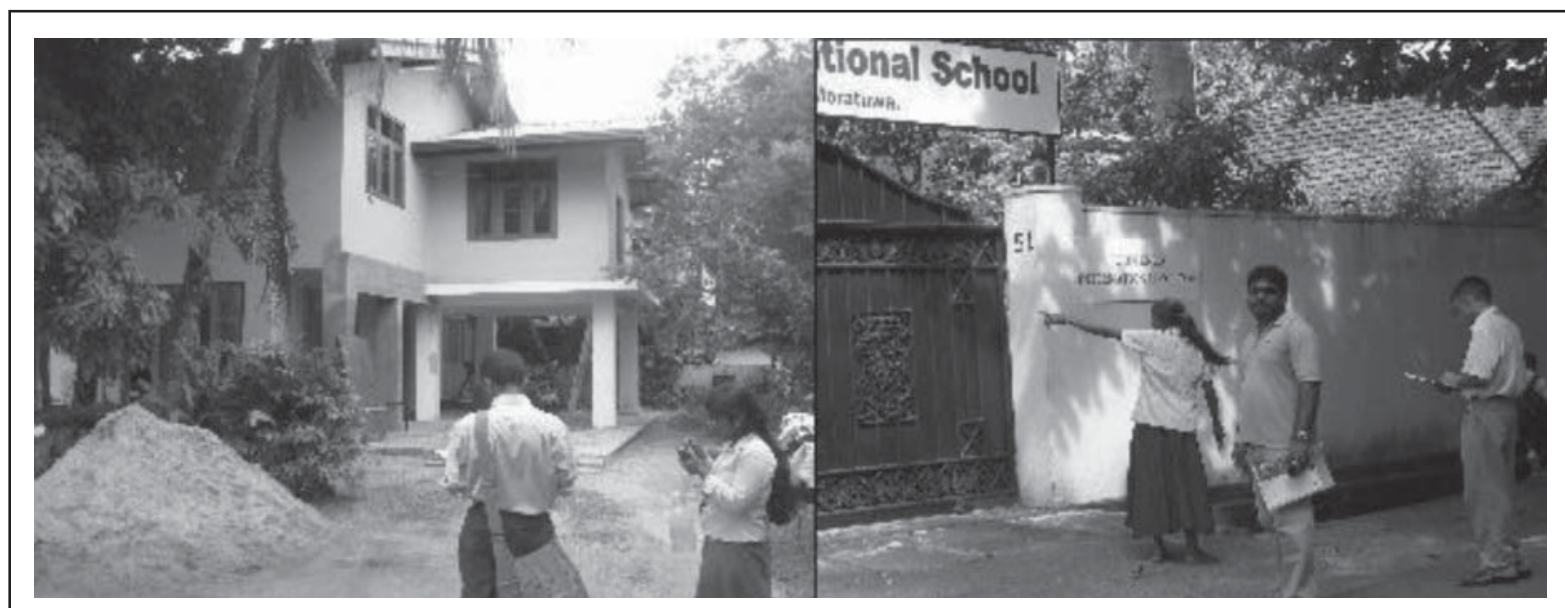

Figure 5 -Data Collection in the Project Area

identified road length using GPS tracks was $52.9 \mathrm{~km}$ having 469 segments. It was noted that some roads which were covered by vegetation had not been identified properly while the narrow roads also had not been properly captured through the visual interpretation of google image. The overall error in road identification in the project area using satellite views was $18.6 \%$ under estimation of length.
Planning and execution of data collection form preparation, field work and data entering was supervised closely at two levels. One was above the data collector and data entry level with support for literature survey, planning, preparation and organizing. This was identified as the Project leadership. The other was the overall supervision which could be described as the efforts to ensure direction,

Table 3 - Road Distribution of the Study Area

\begin{tabular}{|c|c|c|c|c|c|c|}
\hline Type & $\begin{array}{l}\text { Average } \\
\text { Width (m) }\end{array}$ & $\begin{array}{l}\text { Road } \\
\text { Segments }\end{array}$ & $\begin{array}{l}\% \text { of Road } \\
\text { Segments }\end{array}$ & Length (m) & $\%$ of Length & Road Area (m2) \\
\hline Class 1: 4-lane & 12.2 & 1 & 0.21 & 1,118 & 2.1 & 13,630 \\
\hline Class 2: 2-Lane & 6.1 & 18 & 3.84 & 10,152 & 19.2 & 61,884 \\
\hline $\begin{array}{l}\text { Class 3: } 1 \text { lane with } \\
\text { overtaking facility }\end{array}$ & 3.0 & 57 & 12.15 & 9,146 & 17.3 & 27,876 \\
\hline $\begin{array}{l}\text { Class } 4: 11 \text { lane, no } \\
\text { overtaking facility }\end{array}$ & 2.4 & 23 & 4.90 & 1,184 & 2.2 & 2,887 \\
\hline $\begin{array}{l}\text { Class 5: foot/motor bicycle } \\
\text { paths }\end{array}$ & 1.2 & 366 & 78.04 & 25,848 & 48.8 & 31,512 \\
\hline Private Roads & 1.8 & 4 & 0.85 & 5,473 & 10.4 & 10,009 \\
\hline Total & & 469 & 100.0 & 52,920 & 100.0 & 147,797 \\
\hline
\end{tabular}

Under estimation of road segments was approximately $36.9 \%$. Total land use percentage including all roads and buildings indicate that only about $76 \%$ of the study area is either garden, water or natural vegetation.

\subsection{Data Collection}

Details of feature data collection in each zone and the time consumed for data collection are shown in the Table 5. Total road length and road segments in different zones show an overlapping of roads which was sometimes unavoidable since road centrelines were taken as the boundary of data collection zones and because a deliberate overlap was allowed for data verification purpose. quality, systematic approach and verification. Number of hours of project interaction by data collectors, data entry and extraction, project leaders and overall supervisor were recorded in order to obtain an assessment of the person day effort that was required GIS Database preparation. An attempt was taken to obtain the input requirement estimations through a weighted average concept enabling the understanding order of magnitude of the data collection resources. Overall supervisor of the project was given a weight of 5 while the project leader efforts was weighted by a factor of 3 which were decided after discussions and considerations with respect to education, experience, and current remuneration of each 


\begin{tabular}{|c|c|c|c|c|c|c|c|c|c|c|c|}
\hline uos.ıəd/.nou/ł!̣u & $H$ & $\infty$ & $\stackrel{M}{\longrightarrow}$ & $\exists$ & $\stackrel{10}{2}$ & ๑ & $\cong$ & 은 & $\wedge$ & + & $a$ \\
\hline dno.э/Кер/ґ!u & $\stackrel{\infty}{+}$ & ร & กิ & సે & $\stackrel{\vartheta}{=}$ & $\stackrel{\infty}{\vec{N}}$ & તే & $\ddot{d}$ & 守 & สู & \\
\hline 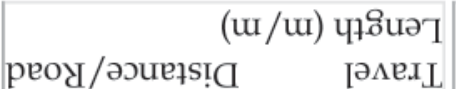 & $\Lambda$ & 으 & 10 & $\infty$ & $\infty$ & $N$ & $\infty$ & $\infty$ & $m$ & $N$ & H \\
\hline Кер/ dno.গ /ı!u & $\stackrel{\infty}{+}$ & ร & กิ & స్తి & $\stackrel{\vartheta}{\ni}$ & $\stackrel{\infty}{\vec{\sim}}$ & సై & \begin{tabular}{l}
$\infty$ \\
\multirow{N}{*}{}
\end{tabular} & 今 & $\stackrel{\text { త్ }}{ }$ & \\
\hline 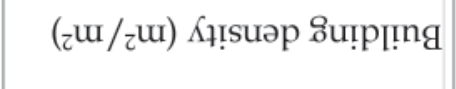 & สิ & సั. & సָ & กิ & $\stackrel{\sharp}{\leftrightarrows}$ & $\stackrel{9}{\circ}$ & స్ & $\stackrel{ }{\circ}$ & $\stackrel{10}{?}$ & $\stackrel{10}{?}$ & \\
\hline 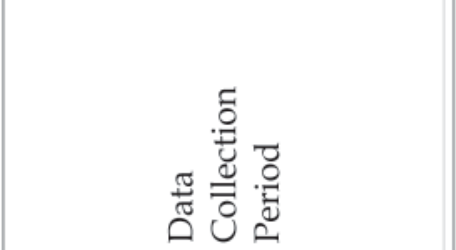 & 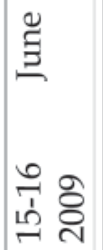 & 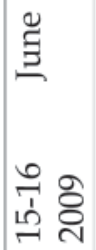 & 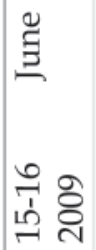 & 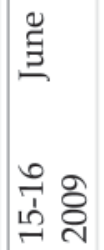 & 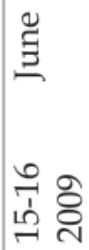 & 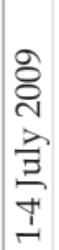 & 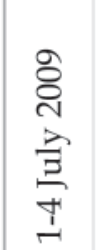 & 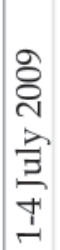 & 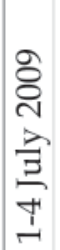 & 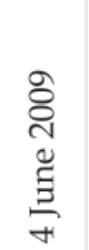 & \\
\hline s.moH tnduI & 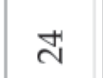 & 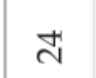 & 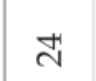 & 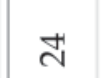 & $\stackrel{\bullet}{\sim}$ & 와 & $\cong$ & ఫ & 옥 & @ి & $\underset{\sigma}{\infty}$ \\
\hline 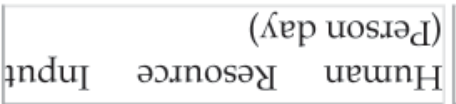 & 6 & 0 & 0 & $\bullet$ & 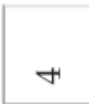 & নి & $\stackrel{0}{\sim}$ & $\cong$ & તิ & ๑ & ડָ \\
\hline (uos.rəd /s $\Lambda$ ep) sKe & $N$ & $N$ & N & N & $N$ & H & + & $m$ & H & $r$ & $\stackrel{2}{2}$ \\
\hline 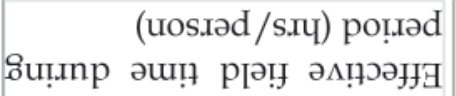 & $\infty$ & $\infty$ & $\infty$ & $\infty$ & $\infty$ & 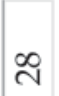 & $\stackrel{\sim}{\sim}$ & $\bar{\lambda}$ & 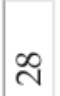 & Ln & $\stackrel{\text { 음 }}{\longrightarrow}$ \\
\hline sdno.r & - & - & - & - & - & -1 & - & - & - & $N$ & \\
\hline 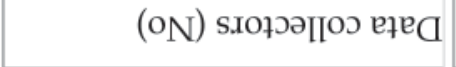 & $\infty$ & $m$ & $\infty$ & $\infty$ & $N$ & เ & + & H & 10 & ๑ & $\infty$ \\
\hline 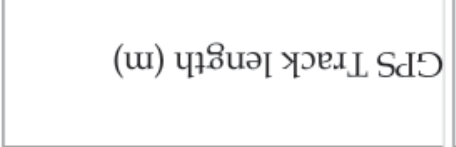 & 菙 & 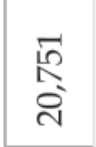 & $\stackrel{\substack{\mathfrak{N} \\
=}}{=}$ & बू & $\overrightarrow{\nabla n}$ & $\begin{array}{l}8 \\
\stackrel{0}{0} \\
\stackrel{10}{\longrightarrow}\end{array}$ & $\begin{array}{l}\text { ֻे } \\
\text { নे }\end{array}$ & 롱 & $\frac{\text { का }}{\overrightarrow{7}}$ & $\begin{array}{l}\infty \\
\substack{\infty \\
0 \\
0 \\
0}\end{array}$ & $\begin{array}{l}\text { \& } \\
\text { a } \\
\text { ה్ర }\end{array}$ \\
\hline (u) чғвиวา реоу & ลิ & 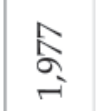 & $\frac{\text { a }}{\stackrel{4}{4}}$ & $\frac{n}{n}$ & 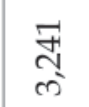 & $\begin{array}{l}\text { స్రి } \\
\text { å }\end{array}$ & $\begin{array}{l}\sqrt[5]{n} \\
\text { a }\end{array}$ & $\begin{array}{l}\hat{0} \\
\text { مإ } \\
\infty\end{array}$ & 总 & 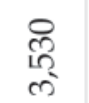 & \\
\hline$\left(\mathrm{oN}_{\mathrm{N}}\right.$ ) słuəuôs speoy & $\infty$ & $\stackrel{2}{2}$ & ले & तै & 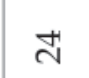 & $\stackrel{\llcorner}{\infty}$ & $\underset{\exists}{\exists}$ & 共 & $\stackrel{ }{\exists}$ & $\vec{\sigma}$ & \\
\hline (ح) & $\begin{array}{l}\text { สิ } \\
\text { ๙ }\end{array}$ & 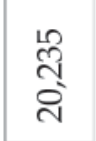 & $\begin{array}{l}\vec{N} \\
\text { ¿े }\end{array}$ & 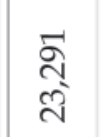 & $\begin{array}{l}\overrightarrow{0} \\
\stackrel{-i}{-1}\end{array}$ & $\begin{array}{l}\vec{ন} \\
\stackrel{\text { I }}{N}\end{array}$ & סे & $\begin{array}{l}\vec{b} \\
\stackrel{2}{N} \\
\text { N }\end{array}$ & 華 & लू & 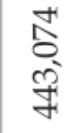 \\
\hline (oN) sout!p!ng & 능 & $\stackrel{\infty}{\rightleftharpoons}$ & ঠి & $\stackrel{\infty}{\stackrel{\circ}{N}}$ & $\ddot{\sim}$ & $\underset{\infty}{N}$ & సิ & $\infty_{\infty}^{\infty}$ & $\infty$ & 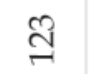 & $\overrightarrow{\text { in }}$ \\
\hline 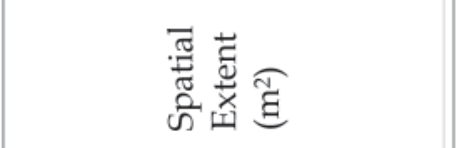 & 总 & $\begin{array}{l}\text { F } \\
0 \\
\infty \\
\infty\end{array}$ & 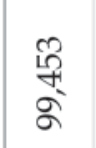 & 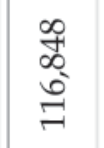 & $\begin{array}{l}\text { gे } \\
\text { 点 } \\
\text { - }\end{array}$ & $\begin{array}{l}\text { مे } \\
\text { ळे } \\
\text { ले }\end{array}$ & $\begin{array}{l}4 \\
1 \\
\infty \\
\infty \\
\infty\end{array}$ & 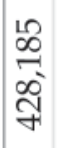 & \begin{tabular}{l}
$\infty$ \\
\multirow{2}{\alpha}{} \\
$\overline{1}$ \\
in
\end{tabular} & $\begin{array}{l}\text { D } \\
\text { 离 } \\
\text { d্ } \\
\text { d }\end{array}$ & 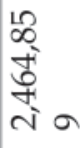 \\
\hline $\begin{array}{l}\text { Ө } \\
\text { ปั } \\
\text { N่ }\end{array}$ & $\vec{b}$ & $\dot{v}$ & $\begin{array}{l}m \\
1 \\
0\end{array}$ & $\begin{array}{l}4 \\
1 \\
1 \\
ن\end{array}$ & $\begin{array}{l}L ? \\
1 \\
ن\end{array}$ & $\vec{H}$ & $\stackrel{N}{H}$ & $\stackrel{P}{\mathscr{P}}$ & $\stackrel{H}{H}$ & 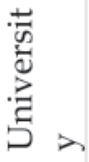 & $\underset{\Xi}{0}$ \\
\hline
\end{tabular}


contributor. Efforts by different contributors and the assigned weights are given in Table 4. The total average-person-day input for the entire data collection activity could be estimated as 330. This also provides a manager with an easy guide to plan a GIS database preparation project by identifying resource person. The data-collector hourly inputs varied between days due to travel distances, familiarity of the area, cooperation of the stakeholders etc... Rate of Building Data collection considering the hourly inputs indicated an average value of nine units per person per hour. Observing the zonal data

Table 4 - Contribution of Efforts by Various Personnel

\begin{tabular}{|l|l|l|l|l|}
\hline Item & Input Description & $\begin{array}{l}\text { Number of } \\
\text { Person } \\
\text { Hours }\end{array}$ & $\begin{array}{l}\text { Assigned } \\
\text { Averaging } \\
\text { Weight }\end{array}$ & $\begin{array}{l}\text { Number of } \\
\text { average person } \\
\text { days }\end{array}$ \\
\hline 1 & Data Collection & 618 & 1 & 77 \\
\hline \hline 2 & Data Entry and Extraction & 1736 & 1 & 217 \\
\hline 3 & Logistics Support & 69 & 1 & 9 \\
\hline 4 & Project Leadership & 36 & 3 & 14 \\
\hline 5 & Overall Supervision & 21 & 5 & 330 \\
\hline
\end{tabular}

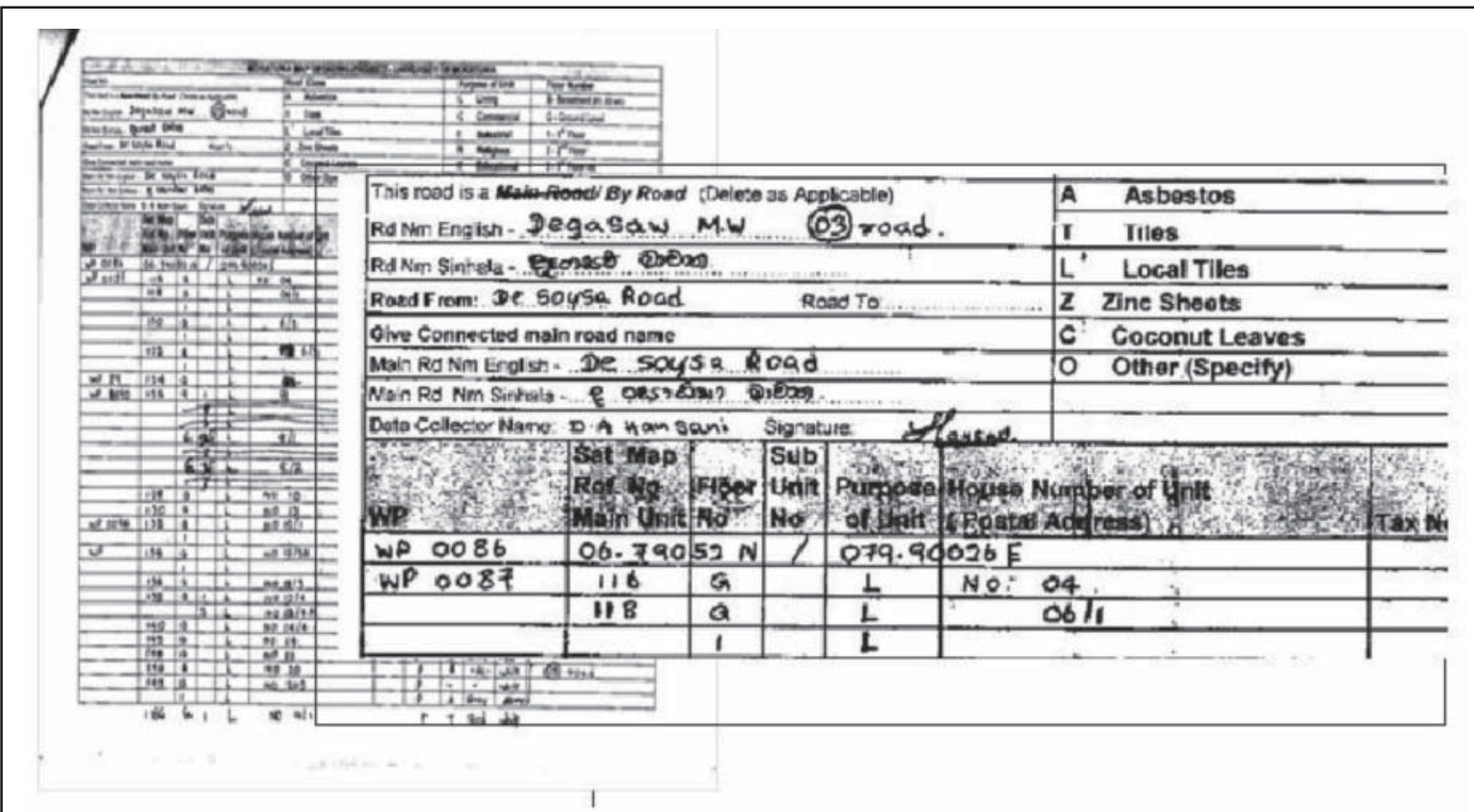

Figure 6 - A completed Data Collection form

requirements. A completed data collection form is shown in Figure 6.

The daily data collection per group varied from an initial 47.5 building units per 3 person group to finally 322 per 4 person group. Building data collection per person per day variation is from approximately 16 when the form and the locations are new to the data collectors, to 81 when the data collectors are well trained and the travel distance from the central office at ICGAT was relatively less. On average the rate of building data collection during the entire field program had been 43 units per day per collection records, it could be noted that the number in the group showed that getting accustomed to the form and terrain had reflected an increase in the speed of data collection as expected through the values do not show a significant difference. In the field data collection program, the time and effort taken for road data capturing was not considered as significant since tracking of paths was done automatically and simultaneously by the Handheld GPS units, while time for recording of road names was treated as 
negligible when compared with that of the buildings.

GPS tracking enabled the identification of actual distance travelled by the data collectors when capturing and verifying building and road units. GPS tracks were downloaded from the handheld units, converted to shape files and then tracks lengths of each travel were computed. In the data collection efforts it was identified that on a few occasions the track data were lost either due to a problem in the equipment or due to the ignorance of the GPS operator. However without making allowances for such data losses, the total number of track lengths was $162.5 \mathrm{~km}$. Zones G1, G2 and G3 had shown a high ratio of track-length to roadlength reflecting delays due to initial difficulties of map orientation and unfamiliarity of data form requiring repeated visits for self clarification by the data collector group. In some zones the distance travelled was equal to the distance to and back. This was noted at two locations; one within the University and the other at zone T-1 which required significant approach of travel. In the case of T1 zone it could be noted that the track data recording has not captured the entire distance travelled. For the entire data collection program, it can be considered that the actual travel distance covered on average, and without considering the road overlaps in Zones, was 3 times the total road length. In case a $10 \%$ track loss is assumed then the ratio would increase to 3.4.

Data collection groups reported a significant time requirement for interaction with the public for building and utility unit identification. Data collection neighbourhood was semi urban and with families having many livelihood issues, neighbourhood issues, and grievances such as non collection of garbage, haphazard garbage disposal, unemployment and inadequency of income, neighbourhood political differences, family rivalry, irritation due to repetitive data collection by various state and research institutions. These caused significant interaction requirements during data collection than that was initially anticipated. Data collectors also needed interaction to ascertain direct data collection from the source. Indirect data collection and verification was also necessary through interaction with the neighbours. Interaction time increased due to the need of establishing the authenticity of individuals and the cause, fulfilling security concerns etc... Data collectors indicated that the elderly, unemployed persons demanded more interaction time.

\subsection{Magnitude and Accuracy}

The field collected data were incorporated in to the GIS. The vector file of Building Polygons and the attribute files consisted of $1.15 \mathrm{Mb}$. The size of road vector file consisting of lines was $80.4 \mathrm{~kb}$.

Verification efforts enabled computation of the percentage of identified data capturing errors and omissions per number of units visited. Average value of errors which was approximately $20 \%$, indicated the need of a more than one screening of outputs from data collection. The following were the activities carried out as part of data checking. I) Data checking during collection II) Checking of completed data sheets at the point of handing over for data entry and III)Data checking during gap filling.

The contribution efforts for Data Collection Entry and Extraction (Table 4) were performed with minimum overlap while logistic support, project leadership and overall supervision was with nearly $75 \%$ overlap. Though specific records were not maintained, available records indicated an approximate consumption of one and a half calendar months for the Geodatabase preparation.

\section{Summary of Results}

\subsection{Data}

Present work in the study area of $22.46 \mathrm{~km}^{2}$ including the premises of Moratuwa University and its surrounding indicated a region with $23.97 \%$ land area consisting of roads and buildings. Total number of building units in the area was 5175 while the entire road length including either foot or motor bicycle paths amounted to $52.9 \mathrm{~km}$. Identification of buildings and roads with the use of Google image captured at an altitude of $300 \mathrm{~m}$ resulted in an over estimation of $20.3 \%$ in building while an under estimation of $18.6 \%$ could be noted in the case of roads. It was estimated that approximately 1.5 calendar months were required for GIS preparation with an average person day input of 330. This work indicated a data collection coverage rate of 5.5ha per averaged person day. The study revealed that over three times the road length should be allowed as the travel distance required for field data collection in a semi urban area having a density of 1960 buildings per $\mathrm{km}^{2}$ and when operated from a location central to all data location zones. 


\subsection{Data Form}

The data form used for the field work very satisfactory because it could be used as a separate A4 sheet. This form has a tabular format for easy data entry and it indicated a pre-coded classification for quick and short entries. Each sheet has a notation guide and enables easy identification of locations and attributes. The form records the details of data entry personnel for quality control purposes.

Data form design requires clear identification of parameters. Therefore prior to design of data collection forms and planning programs it is very important to identify the inputs that are required to deliver desired outputs. The database design requires undertaking the identification of attributes and parameters, data types, formats, size of data, etc... In order to perform the development of a practically useful data collection form. Trial testing of data forms for clarity, completeness and ease of data entry is a very important component of field data collection. The present work needed minor improvements even at the full scale data collection which was commenced after two trial testing. It was recognized that a proper database design should be done well ahead of field data collection and provide sufficient opportunity for field testing so that both the form and the collectors could be tested and trained. Prior to carrying out full scale data collection it is important to ensure a suitable design taking in to account, the features, their attributes and values that are to be collected. These are the key factors that could be taken into consideration when preparations are done for GIS.

\subsection{Data Collection}

Data collection showed that even after training of collectors, there were omissions and errors which required carefully executed corrections and gap filling. Data collection in this work was conducted by groups of different sizes. However the groups of four to five were considered as the best option, which provided similar rates of data capture. In data collection, the major functions are, map reading, identification of a specific feature, use of GPS for way point recording, data entering in the form and verification of the entries.

It was recognised that a group of three to four persons could reasonably minimise the data omissions when handing the maps, GPS and Data form. A group of this size increased the reliability, and also showed better interaction with stakeholders during data collection.
This group showed better discussions among group members to avoid ambiguities. The other advantage was that each member could be assigned separate functions enabling coordinated speeding data collection leading to minimum time loss.

A total of 77 person days were required for field data collection. Overall average person day requirement for the data collection program was computed as 330. Building and road data feature capturing revealed a total of 5384 building sub unit and $52.9 \mathrm{kms}$ of road detail were in existence in a total study area extent of $2.46 \mathrm{~km}^{2}$. Total distance travelled by data collectors computed using the GPS tracks and without making allowances for data recording lapses was $162.5 \mathrm{~km}$. A data collector requirement of approximately 32 person days per $\mathrm{km}^{2}$ and a travel distance of $6 \mathrm{~km}$ per person per $\mathrm{km}^{2}$ were experienced during this field data collection. These values while filling a gap in the area of field data collection provide guidance for future field work planners in similar regions for the development of GIS databases.

\subsection{Verification and Gap Filling}

It is very important to use a geodatabase to verify the captured data up to the recording. In this work, initially the design of data collection form ensured quality by carrying out a literature survey and discussion sessions with experts to identify omissions and improvements which are inline with the study objectives. Data collectors within the group performed data verifications and checked for consistency while data collection work was on going. Intermittent verifications using mobile phones carried out by the research leadership to ensure speed and quality was measured. End of the day data collections were verified at office by quick scans and discussions with data collectors. Methods of visiting house units for detailed checking, facilitated random verifications. Use of roof and wall colour captured with the initial data collection was identified as a very good verification tool because most location verifications could be done without interacting with users of dwelling units. Periodic screening and analysis of the data collection program, are concept and objectives enabled for a systematic gap filling program. Entering data in the forms, incorporation of GPS way points, marking locations on printed maps, and incorporating GPS tracking of data collector paths enhanced the quality of data because these helped to avoid data errors while enabling several 
verification options to maintain accuracy. Training of data collectors on the filling of forms and the use of GPS equipment, carrying out periodic checks on the battery life and GPS settings are specifically identified tasks which enabled the field data verification of field data. In this work even with a very concentrated effort, a loss of digital data was experienced and in such occasions data collection efforts did not require to be repeated due to the availability of manual recording of the base data. The present work experienced the need of capturing interlinked data by both digital and paper based methods to ensure the quality of captured data without a significant time loss.

\subsection{Future studies}

The present work is a case study using a quantitative approach for assessment. It is necessary to carryout several similar studies so that guidelines can be developed for a particular area and for a purpose. In such an effort the following are recommended to be considered.

1. The parameters used for field data collection in this study are for buildings and roads. It is necessary to investigate the needs for other types of field data

2. The recommendations made in this study are based on several trial group compositions. A study specifically designed to determine the effect of the group composition would provide more conclusive results. In such a study it is may be useful to study the effect of a separate set of collectors for gap filling instead of the same collectors as in this study.

3. In this study the Zonal distribution is based on the center line of the roads. During the field work it was noted that there was duplicate travel. It is recommended to study various options for the demarcation of data collection zones.

4. Studies in various regions for various features considering a design for evaluation of data loss are also very important to further strengthen the findings of this research.

\section{Conclusions}

1. A field data program to capture road and building data in a semi urban area for the preparation of a geodatabase could be systematically completed with quantified assessment of resource utilization.

2. Building and Road data capturing rate is about 5.5ha per averaged person day in the study area where land cover by buildings and roads was $24 \%$. Building coverage was 51 units per averaged person day.

3. Field data collection forms designed by clearly identifying the objectives and carrying out rigorous testing using various methods need to ensure clarity and recoding brevity.

4. Field data collection carried out in a systematic manner while consciously making efforts to implement various verification techniques for checking both data capture and recording using combined paper based and digit methods ensured a quality enhancement in the data collection

5. The field data collection travel distance was approximately 3-3.4 times the roads length in a semi urban setting having an average building density of about 2100 buildings per $\mathrm{km}^{2}$.

6. Building unit identification from satellite view was a $20.3 \%$ over estimation while road length had $18.6 \%$ under estimation.

\section{References}

1. Evans Steve, A prototype environmental information system for London, Centre for Advanced Spatial Analysis, University College London, 1-19 Torrington Place, Gower Street, London, ISSN: 1467-1298, 1999

2. Peter F. Dale and John D. McLaughlin, Land Information Management; An introduction with specific reference to cadastral problems in Third word countries, Chapter 1

3. Fikir Alemayehu, Nurhussen Taha, Jan Nyssen, Atkilt Girma, Amanuel Zenebe, Mintesinot Behailu, Seppe Deckers, Jean Poesen, "The impact of watershed management on land use and land cover dynamics in Eastern Tigray (Ethiopia)" Resources, Conversion and Recycling, Volume 53, Issue 4, Page 192-198, February2009.

linkinghub.elsevier.com/retrieve/pii/S0921344 908002036 [accessed 16/12/2010]

4. Fu Yang, Guangming Zeng, Chunyan Du, Lin Tang, Jianfei Zhou and Zhongwe Li, "Spatial Analysing System for Urban land-use management based on GIS and multi - criteria assessment modelling", Progress in Natural Science Volume 18, Issue 10, 10, Pages 12791284, $\quad 10 \quad$ October 2008 
linkinghub.elsevier.com/retrieve/pii/S1002007 108002475 [accessed 17/12/2010]

5. "Guidelines for Designing Data Collection and Sharing Systems for Co-Managed Fisheries", FAO Fisheries Technical Paper, 494/2, Food and Agriculture Organisation, of the United Nations, Rome, 2005

6. Karunathilleka. G.R.N., Wijesekera N.T.S., "Key Issues and Recommendations Related to Field Data Collection in Soil Erosion Assessment", Journal Tropical Agricultural Research, Post Graduate Institute of Agriculture, University of Peradeniya, Sri Lanka, Vol.13, ISSN: 1016 - 1422, November 2001

7. Kofi YEBOAH, Ghana and Linda JOHANSSON, Sweden, "Urban Management Land Information System (UMLIS): Facing Urban Challenges through Efficient Revenue Collection, Facing the Challenges - Building the Capacity", FIG Congress 2010, Sydney, Australia, 11-16 April 2010

8. Tsouchlaraki A., Achilleos G., Nikolidakis A., Nasioula Z., "Building a Geo-Database for Urban Road Network Environmental Quality", 3rd INTERNATIONAL CONFERENCE ON CARTOGRAPHY AND GIS, Nessebar, Bulgaria, 15-20 June, 2010, www.cartographygis.com/pdf/86_Achilleos_paper.pdf accessed 31/1/2011,

9. V. Mathiyalagan, S. Grunwald, K.R.Reddy and S.A. Bloom. "A Web GIS and geodatabase for Florida's wetlands", 2004

10. Yeboah K., and Johansson L., "Urban Management Land Information System, UMLIS: Facing Urban Challenges through Efficient Revenue Collection", FIG Congress 2010; Facing the Challenges - Building the Capacity, Sydney, Australia, 11-16 April 2010

11. Bhat M V., "Methodology For Creation of Land Information Management System, Survey of India, Indian Cartographer 2003" Hyderabad, www.incaindia.org/technicalpapers/8.pdf accessed on $17 / 1 / 11$,

12. "Biodiversity and Protected Areas Management Project (BPAMP)", Ranger-Based Data Collection, A reference guide and training manual for protected area staff in Cambodia, Department of Nature Conservation and Protection, Ministry of Environment, Phnom Penh, Cambodia, June 2006, ( available at www.ecostats.com/software/mist/RBDC_ma nual.pdf Visited 17th Jan 2011)

13. "Data Verification, The Teacher", http://www.theteacher99.btinternet.co.uk/the teacher/newalevel/cp2_10_2.htm [accessed $18 / 12 / 10)$

14. Montana. L and Spencer .J., "Malaria Indicator Survey, Incorporating Geographic Information into MEASURE Surveys: A Field Guide to GPS
Data Collection", The University of North Carolina at Chapel Hill Carolina Population Center., August 2004, www.searo.who.int/.../malaria_indicator_surv ey_malariasurvey_FGuideGPSdata.pdf , visited 17th Jan 2011

15. OpenGL, "Moratuwa Sri Lanka", January 2005, Kh.google.com. visited January 102009

16. "Projo Danoedoro", Extracting Land use Information Related to Socio Economic Functions from Quickbird Imagery, 2006, http://www.gisdevelopment.net/application/ lis/overview/ma06_137.htm [accessed 18/12/10]

17. "Sarasota County Government-GPS Procedures Guideline", GPS Procedures Manual, Sarasota County Government, 2002 http://khup.com/download/6_keywordguideline-gis-field-data-collection-17 Jan 2011

18. T.Raja Rao, "LIS Issues, technologies and standardization", http://www.gisdevelopment.net/application/ lis/overview/lisrp0011.htm [accessed $17 / 12 / 2010]$ 